\title{
Canadian Association of Gastroenterology Practice Guideline for granting of privileges to perform gastrointestinal endoscopy
}

H Miller MacSween MD FRCPC

$\mathrm{T}$ he purpose of this statement is to provide guidelines to assist hospital credentialling committees in their task of granting privileges to perform gastrointestinal endoscopy. Endoscopy of the gastrointestinal tract has evolved over the past 30 years as a potent tool to assist in the evaluation, diagnosis and therapy of patients with gastrointestinal tract disorders. Although gastrointestinal endoscopy was initially developed as a purely diagnostic tool, the development of therapeutic endoscopic techniques has dramatically expanded the role of gastrointestinal endoscopy, frequently to a therapeutic one. In setting guidelines for training and credentialling one must recognize that, excluding flexible sigmoidoscopy, endoscopists should be well trained in therapeutic endoscopy.

Competency in performing endoscopic procedures requires competency in the technical, interpretive and cognitive aspects of endoscopy, and the capability to integrate endoscopic findings into clinical practice. The six principals of endoscopic training are understanding of the indications; expeditious performance of procedures; correct interpretation of findings; integration of these findings into therapeutic management plans; avoidance and management of complications; and recognition of personal limitations in performing endoscopic procedures. Training should be comprehensive and provide a working knowledge of the patho-

\section{SPONSORS AND VALIDATION}

This practice guideline was developed by H Miller MacSween MD FRCPC and was reviewed by:

- The Practice Affairs Committee

- Canadian Association of Gastroenterology (CAG) Governing Board

- CAG Endoscopy Committee

- CAG Program Directors Committee

physiology, diagnosis and management of digestive diseases for which endoscopic procedures are indicated.

Training and credentialling guidelines need to reflect the changes that have occurred in the field of gastrointestinal endoscopy. There is little need for the occasional endoscopist in Canada given the availability of well trained and experienced endoscopists throughout the country. It is clear that it is both care-effective and cost-effective for the Canadian public to have endoscopies performed by practitioners who are adequately trained, in centres that are appropriately equipped to handle the diagnostic and therapeutic aspects of these procedures. The following guidelines - in terms of training, credentialling and maintenance of competence reflect these issues. 


\section{GUIDELINES FOR TRAINING IN GASTROINTESTINAL ENDOSCOPY}

Training guidelines should be divided into those required for flexible sigmoidoscopy, gastroscopy, colonoscopy and endoscopic retrograde cholangiopancreatography (ERCP). Training should take place within institutions having Royal College accredited programs in gastroenterology, surgery and/or pediatric gastroenterology. However, in some circumstances endoscopic training may be sought by practitioners who are not training in one of the above specialties. The guidelines for training should apply to all individuals who are performing gastrointestinal endoscopy whether they are gastroenterologists, surgeons, internists, pediatricians or family physicians. Accordingly, any practitioner performing gastrointestinal endoscopy should meet the minimum training guidelines.

Because endoscopic skills are gradually acquired through the repeated performance of the procedure under appropriate supervision, training should progress through a continuum of graded responsibility and diminishing supervision as the trainee acquires the appropriate technical and cognitive skills to perform the procedure. This progression will vary from trainee to trainee in accord with his or her individual skills.

Training in gastrointestinal endoscopic procedures not only involves learning the technical aspects of the procedure, but also thoroughly understanding the underlying pathology and the appropriate indications for intervention. It must be recognized that procedures carry some risk and are not without complication. Training, therefore, must include a through understanding of the recognized complications of endoscopic procedures and their appropriate management.

Guidelines for training should consider both a time component and a minimum number of supervised procedures that should enable most trainees to acquire the knowledge and technical skills to be minimally competent in these procedures. The number of procedures that a trainee must perform to obtain an acceptable level of competence varies widely, depending on the procedural complexity, individual aptitude and quality of instruction. Although somewhat arbitrary, proposing guidelines for the number of procedures that should be performed before evaluation for certification is of value. Guidelines expressed as 'minimal competence' have been misinterpreted in the past to mean that all trainees are competent at that number. It is preferred to offer the numbers as thresholds or triggers for assessing competence. Some time after achieving and documenting the threshold number, the trainee may request that a program training director assess competence with a view to certification. It would be unusual for training directors to consider certification below these threshold figures.

It is emphasized that short courses of endoscopy training provide neither the experience nor the cognitive skills required to diagnosis and treat digestive diseases properly. Granting hospital privileges to a physician with inadequate qualifications obviously has important patient care, economic and legal implications, particularly when procedures are expensive and invasive. The goal is to assure that we have competent endoscopists to serve the Canadian public in both a care-effective and cost-effective manner.

Diagnostic flexible sigmoidoscopy: Because flexible sigmoidoscopy represents a primarily diagnostic gastrointestinal endoscopic procedure and does not involve conscious sedation, it requires less commitment of time to learn than the other procedures. Training for routine diagnostic, flexible sigmoidoscopy requires a minimum of 25 supervised procedures to gain competency, and should be a part of a two- to threeweek training program during which the trainee should gain a basic understanding of distal endoscopy, the common disorders of the lower gastrointestinal tract and the appropriate indications for endoscopic intervention.

Therapeutic procedures such as polypectomy would not be included as part of this training and should be performed only by practitioners trained in colonoscopy.

Gastroscopy: Individuals training in the performance of upper gastrointestinal endoscopy (gastroscopy) should not only be able to perform the diagnostic component of the procedure competently, safely and expeditiously, but also be able to perform basic hemostasis of nonvariceal upper gastrointestinal hemorrhage and simple bougienage of esophageal strictures. Other procedures, such as hemostasis of variceal hemorrhage, tumour debulking, gastric polypectomy, pneumatic dilation for achalasia, and esophageal stent placement should be left to specialists who have a particular interest and advanced training in these procedures. To acquire basic competency a minimum of 100 supervised gastroscopies are required. In terms of therapeutic procedures, training should include 20 cases each of nonvariceal hemorrhage and esophageal dilations. This should be part of a training program that is a minimum of three to four months in duration during which time the trainee must acquire a sound knowledge of upper gastrointestinal pathology and the appropriate indications for diagnostic and therapeutic intervention.

Colonoscopy: Individuals training in colonoscopy should not only be able to perform a full diagnostic study competently, safely and expeditiously, but also be able to perform snare polypectomy and basic hemostasis. Given the greater technical difficulty and higher risk of complications associated with these procedures, individuals performing full colonoscopy with or without polypectomy should acquire these skills as part of specialty training in either gastroenterology, colorectal surgery or pediatric gastroenterology. Within the auspices of an appropriate specially training program, a minimum of 125 colonoscopic procedures should be required, including at least 20 snare polypectomies.

ERCP: ERCP should be considered an advanced therapeutic procedure because there are only rare indications for a purely diagnostic study. Accordingly, individuals training in ERCP should be well versed and competent in the basic therapeutic procedures of sphincterotomy, stone extraction and biliary drainage with either endoscopically placed stents or nasobiliary tubes. Given the difficulty and potential for complications associated with ERCP procedures, ERCP training should be part of a third year of dedicated, advanced thera- 
peutic endoscopic training, following a speciality residency in either gastroenterology or surgery. A minimum of 180 ERCPs, of which $60 \%$ to $70 \%$ should be therapeutic cases, should be required.

\section{CREDENTIALLING IN GASTROINTESTINAL ENDOSCOPY}

It is recognized that credentialling is the role of individual institutions or regional boards, whose major obligation is to protect patients. Credentialling in a given institution should be based on the successful completion of an accredited endoscopic training program. Only an accredited program provides the education, training and knowledge needed to assure that the clinical indications for endoscopies are met, that they are performed safely and effectively, and that the information obtained from the procedure is applied to the full benefit of the patient. Inadequate training can result in misinterpreted endoscopic findings, an inappropriate treatment plan and potential harm to the patient. Eventually the patient may require further referral with the likelihood of further endoscopy. Granting endoscopy privileges is an endorsement of the physician's competence and ability to carry out endoscopic procedures to diagnose and treat digestive disorders. Therefore, the hospital must ascertain that the physician applying for endoscopic privileges has acquired the knowledge, training and experience as described above.

If the applicant has not successfully completed an accredited endoscopic training program, the hospital should obtain sufficient evidence that he or she has had equivalent formal training. The applicant's endoscopic director should confirm in writing the training, experience (including the number of cases for each procedure for which privileges are requested) and observed level of competency. Attendance at short endoscopy courses is not considered an acceptable substitute in the development of equivalent competency.

\section{PROCTORING AND HOSPITAL ENDOSCOPIC PRIVILEGES}

A proctor acts as a monitor to evaluate the technical and cognitive skills of another physician. Recognizing the limitations of written reports, proctoring of applicants for privileges in gastrointestinal endoscopy by a qualified, unbiased staff endoscopist may be desirable, especially when competency for a given procedure cannot be adequately verified by submitted written material. Proctoring may also be appropriate for incumbent medical staff members who hold privileges for an endoscopic procedure but who have performed few procedures over an extended period of time, or when proctoring may be one of several appropriate follow-up actions when a potential practice problem is identified by the hospital's quality assurance or risk management programs.

The proctor should prepare a confidential written report for use by the credentials committee. Proctors may be chosen from existing endoscopy staff or from regional or national endoscopic societies.

\section{RENEWAL OF ENDOSCOPIC PRIVILEGES}

To assist the hospital credentialling body in the ongoing renewal of privileges there should be a mechanism for monitoring endoscopic performance; this should be done through quality assurance mechanisms or through a multidisciplinary endoscopic committee. Performance monitoring should include monitoring endoscopic use, diagnostic and therapeutic benefits to patients, complications and tissue review.

Continuing medical education related to endoscopy should be required as part of the periodic renewal of endoscopic privileges. Attendance at local or national meetings is encouraged.

\section{BIBLIOGRAPHY}

Achord JL. The credentialing process. Rational decisions of hospital committees for granting of privileges in gastrointestinal endoscopy. Am J Gastroenterol 1987;82:1064-5.

Alberta Society of Gastroenterology. Guidelines for Training and Credentialing in Gastrointestinal Endoscopy. Alberta Society of Gastroenterology.

American College of Physicians Health and Public Policy Committee. Clinical competence in colonoscopy. Ann Intern Med 1987;107:772-4.

American College of Physicians Health and Public Policy Committee. Clinical competence in diagnostic ERCP. Ann Intern Med $1988 ; 108: 142-4$.

American College of Physicians Health and Public Policy Committee. Clinical competence in diagnostic esophagogastroduodenoscopy. Ann Intern Med 1987;107:937-9.

American College of Physicians Health and Public Policy Committee. Clinical competence in the use of flexible sigmoidoscopy for screening purposes. Ann Intern Med 1987;107:589-91.

American Gastrointestinal Association. Position statement on hospital credentialing standards for physicians who perform endoscopy. AGA News 1993; 7:5.

American Society for Gastrointestinal Endoscopy. Alternate Pathways to Training in Gastrointestinal Endoscopy. Manchester: American Society for Gastrointestinal Endoscopy, 1995.

American Society for Gastrointestinal Endoscopy. Appropriate Use of Gastrointestinal Endoscopy. A Consensus Statement from the AGE. Manchester: American Society for Gastrointestinal Endoscopy, 1992.

American Society for Gastrointestinal Endoscopy. Appropriate Use of Gastrointestinal Endoscopy. An Information Resource Manual. Manchester: American Society for Gastrointestinal Endoscopy, 1992.

American Society for Gastrointestinal Endoscopy. Gastrointestinal Endoscopy. Diagnostic and Therapeutic Procedures. An Information Resource Manual. Manchester: American Society for Gastrointestinal Endoscopy, 1989.

American Society for Gastrointestinal Endoscopy. Principals of Training in Gastrointestinal Endoscopy. Manchester: American Society for Gastrointestinal Endoscopy, 1992.

American Society for Gastrointestinal Endoscopy. Proctoring and hospital endoscopy privileges. Gastrointest Endosc 1992;38:666-7.

American Society for Gastrointestinal Endoscopy. Quality Assurance of Gastrointestinal Endoscopy. An Information Resource Manual. Manchester: American Society for Gastrointestinal Endoscopy.

American Society for Gastrointestinal Endoscopy. A summary statement on endoscopic training. Gastrointest Endosc 1992;38:6.

Axon AT, Bell GD, Jones RH, Quine MA, McCloy RF. Guidelines on appropriate indications for upper gastrointestinal endoscopy. BMJ 1995;310:853-6.

Bailey RJ, Barkun A, Brow J, et al. Consensus in Endoscopy. Can J Gastroenterol 1996;10:237-42.

Baillie J, Ravich WJ. On endoscopic training and procedural competence. Ann Intern Med 1993;118:73-4.

Bond JH. Evaluation of trainee competence. Gastrointest Endosc Clin North Am 1995;5:337-46.

Cass OW, Freeman ML, Peine CJ, et al. Surgeons and GI Fellows do not differ in the acquisition of endoscopy skills during training. Gastrointest Endosc 1994;40:P39. (Abst) 
Cass OW, Freeman ML, Peine CJ, Zera RT, Onstad GR. Objective evaluation of endoscopy skills during training. American College of Physicians 1993. Ann Intern Med 1993;118:40-4.

Jowell PS. At least 180 ERCPs are needed to attain competence in diagnostic and therapeutic ERCP. Gastrointest Endosc 1996;43:A875.

Methods of granting hospital privileges to perform gastrointestinal endoscopy. Gastrointest Endosc 1992:38:765-7.

Morrissey JF, Reichelderfer M. Gastrointestinal endoscopy. N Engl J Med 1991;325:1142-9.

Society of American Gastrointestinal Endoscopic Surgeons. Granting of privileges for gastrointestinal endoscopy by surgeons. SAGES Publication 1991:11.

Sivak MV. Advanced training in gastrointestinal endoscopy. Gastrointest Endosc 1992;38:90-1.

Statement on the role of short courses in endoscopic training. Gastrointest Endosc 1988;34(Suppl):14S-5S.

Sundermeyer MS, Murphy PA. Prevention of hospital liability for granting privileges to unqualified physicians. Gastrointest Endosc Clin North Am 1995;5:433-45.

Williams CN. Hospital credentialling standards for endoscopy. Can J Gastroenterol 1995;9:130. 


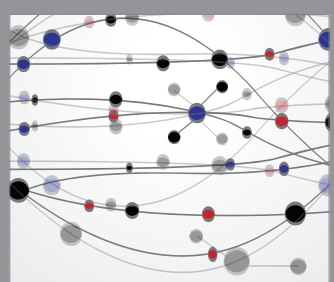

The Scientific World Journal
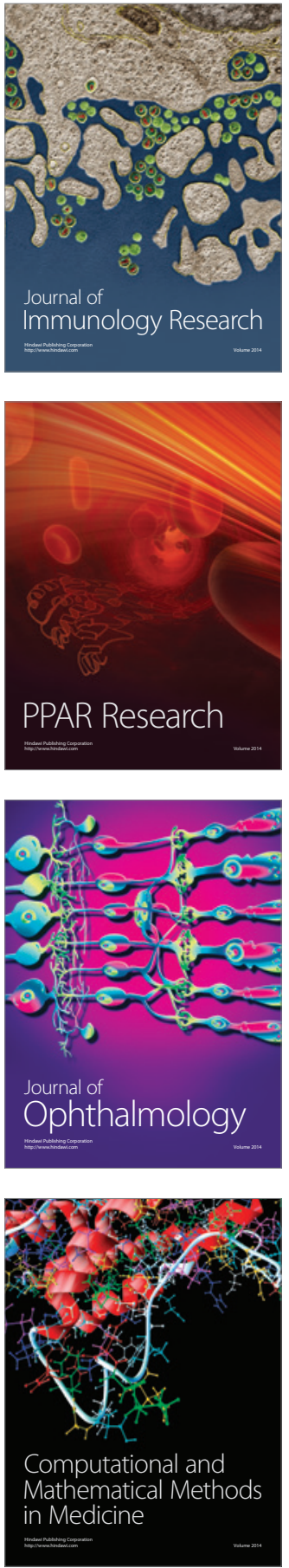

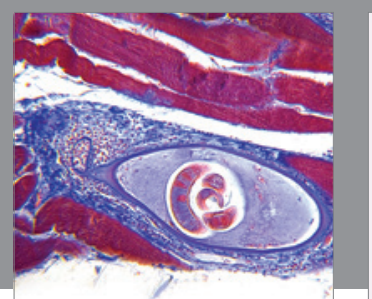

Gastroenterology Research and Practice

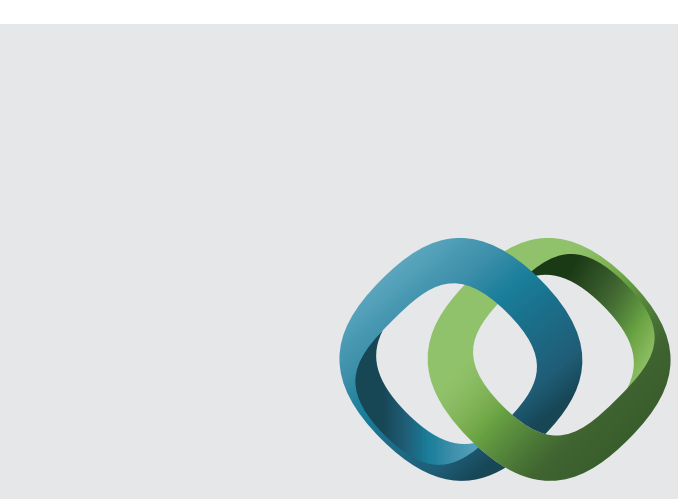

\section{Hindawi}

Submit your manuscripts at

http://www.hindawi.com
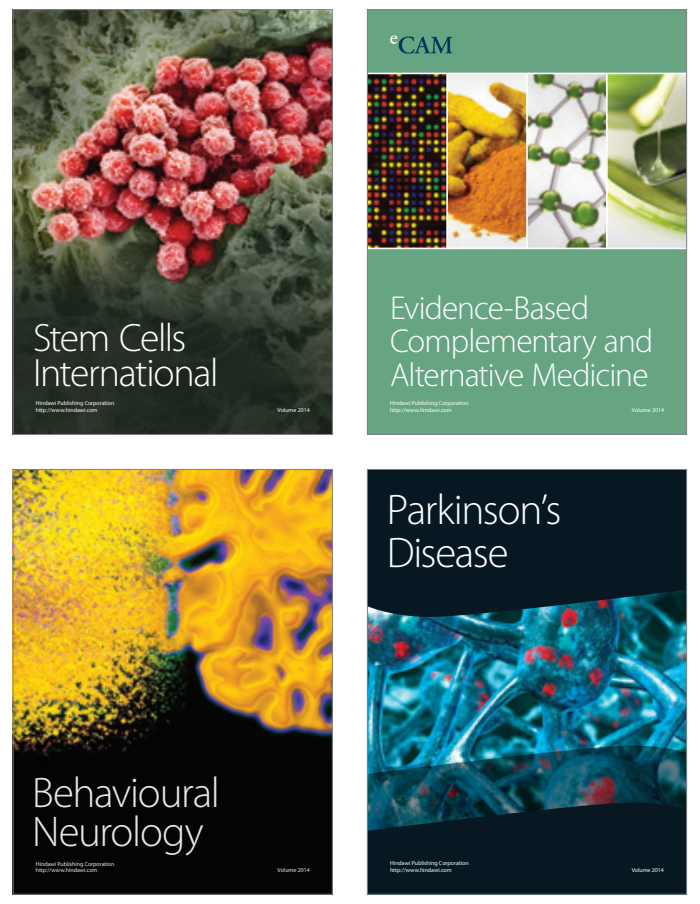
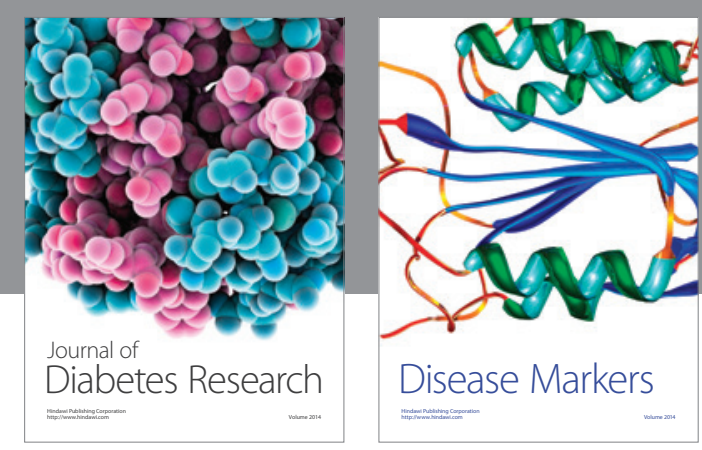

Disease Markers
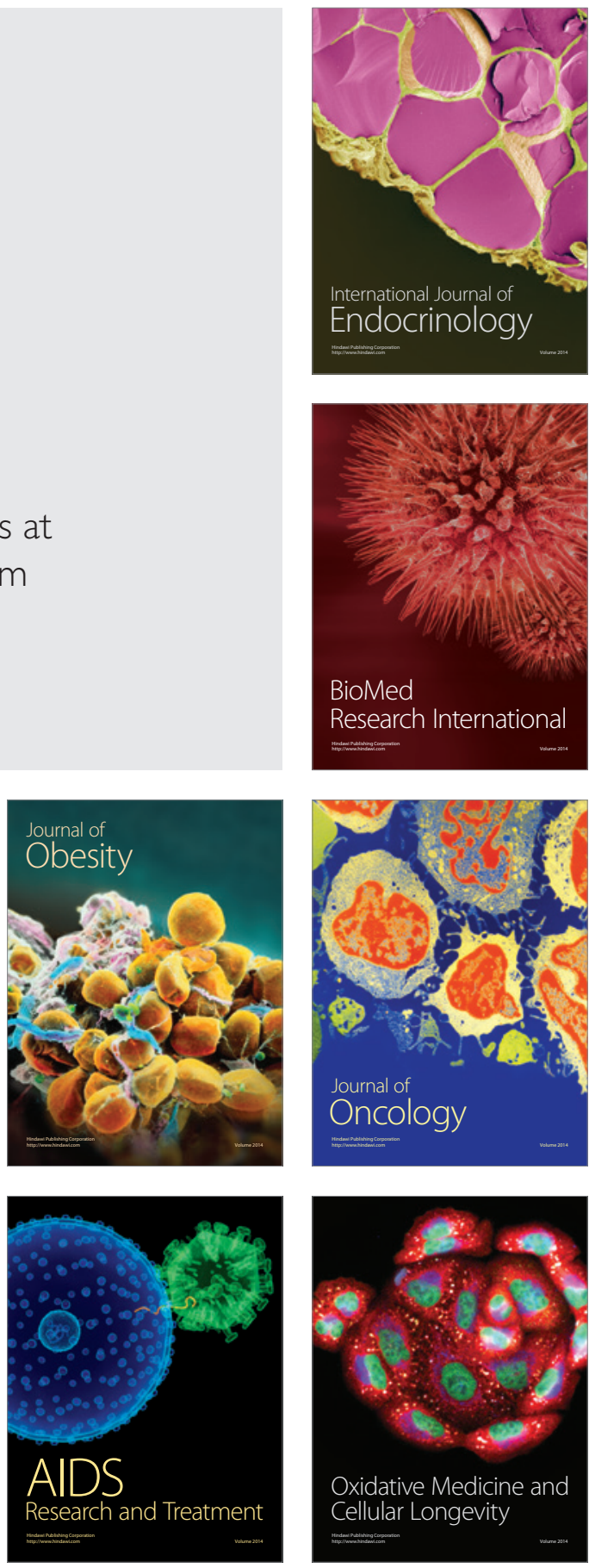